\title{
Just the facts: Organ donation in the emergency department: When you can't save one, save eight
}

\author{
Jennifer Hancock (1), MD, FRCPC, $\mathrm{CCM}^{*}$; Simon Huang, MD, MsC ${ }^{\dagger}$; Samara Zavalkoff, MD, FRCPC, \\ $\mathrm{CCM}^{\ddagger \S}$
}

A 16-year-old female presents to a community emergency room following a suicide attempt by hanging. Prehospital, on arrival of paramedics, the patient was in a pulseless electrical activity rhythm. Paramedics provided advanced cardiac life support for 20 minutes before they obtained return of spontaneous circulation. In the emergency department, she had another 25 -minute cardiac arrest with ultimate return of spontaneous circulation. She is now hemodynamically stable on Levophed $0.2 \mu \mathrm{g} / \mathrm{kg} / \mathrm{min}$. Her neurological exam shows pupils to be $3 \mathrm{~mm}$ and fixed bilaterally, absent cough and gag, and no response to central or peripheral pain. She occasionally triggers 2-3 spontaneous breaths per minute above the set rate on the ventilator. Her CT head scan shows severe anoxic changes and cerebral edema.

\section{KEY CLINICAL QUESTIONS}

\section{What are donation clinical triggers?}

Clinical triggers for organ donation define a potential organ donor and help remind health care teams to initiate referral to their organ donation organization in a timely manner. They have been shown to increase donation rates and allow earlier recognition and mobilization of donation resources. ${ }^{1}$

Patients who meet the following clinical triggers should be considered a potential organ donor and be referred to the organ donation organization ${ }^{2}$ :

1. Ventilated (invasive [intubated/tracheotomy] or noninvasive [bilevel positive airway pressure/continuous positive airway pressure] ventilation) OR circulatory support (medical [vasopressors/inotropes] or mechanical [ventricular assist devices]).

AND

2. Condition with a grave prognosis in which

a. death is imminent

OR

b. A decision to withdraw life sustaining measures has been made (but not yet acted upon).

From the ${ }^{*}$ Department of Critical Care, Dalhousie University, Queen Elizabeth II Hospital, Halifax, NS; ${ }^{\dagger}$ Department of Emergency Medicine, Dalhousie University, Queen Elizabeth II Hospital, CanadiEM, Halifax, NS; ${ }^{\ddagger}$ Department of Pediatrics, McGill University, Montréal, QC; and the ${ }^{\S}$ Division of Critical Care, Montreal Children's Hospital, McGill University Health Centre and Research Institute, Montréal, QC.

Correspondence to: Dr. Jennifer Hancock, Department of Critical Care, Dalhousie University, Queen Elizabeth II Hospital, 1276 South Park Street, Halifax, NS B3H 2Y9; Email: jennifer.hancock@cdha.nshealth.ca

(c) Canadian Association of Emergency Physicians

CJEM 2020;22(2):155-158

DOI 10.1017/cem.2019.456 


\section{What is the role of the emergency department in identifying and referring a patient who meets these} clinical triggers?

In Canada, the gap between availability and need of organs for transplantation remains large. Although there has been a $40 \%$ increase in deceased donation rates over the past decade, Canada still underperforms in comparison to estimated donor potential and other countries. ${ }^{3}$ Failure to identify and refer a potential donor has life-threatening consequences for patients on the transplant waiting list, as one donor on average provides two to four transplants. It also denies donor families the opportunity to find some meaning in an otherwise devasting event. Emergency health care providers are front-line clinicians and often the initial point of contact with potential donors and their families. It is essential that they have the knowledge and resources to identify and refer potential donors in a timely manner. Failure to do so may compromise the entire donation process.

\section{Does this patient meet the clinical triggers and what is the role of the organ donation organization at this point?}

Opportunity for organ donation should be considered an integral part of high-quality, end of life care. This involves referral to an organ donation organization before enacting any comfort measures which may compromise the opportunity to donate (e.g., extubation).

Although initial examination and imaging are suggestive of a poor outcome, early neuroprognostication may be misleading. At this point, the patient is still appropriately receiving active medical care in the emergency department. Any end of life assessments or discussions should only be made after a suitable period of time has allowed for multiple assessments of the patient and prognosis by experts in the patient's medical condition. ${ }^{4}$

Currently, the patient does not meet all clinical triggers, as her prognosis is not yet clear. As such, referral to the organ donation organization is not required. However, early notification/consultation of the organ donation organization may still be appropriate and beneficial. For example, preliminary screening may determine the patient is medically unsuitable and would prevent offering the opportunity to the family when the opportunity does not exist, determine if the patient has registered their intent to donate, or allow travel time for a donation coordinator to offer on-site support to the family and team. ${ }^{2}$

\section{What are key considerations for medical support while the patient is still in the emergency department?}

At this stage, the goal is physiological stability and recovery of the patient. The goal does not yet include preserving the opportunity to donate. Consideration should be given to transferring the patient to another location (e.g., intensive care unit) or institution (e.g., advanced neurocritical care center), as required, to ensure the above supports are expertly administered. While waiting for transfer, neuroprotective measures should be maintained to prevent secondary neurological injury.

If the patient is assessed by experts in the emergency department and the injury is deemed to be nonsurvivable, or the patient has progressed to neurological death, normal physiological parameters should still be maintained until the patient is able to be assessed for the possibility of donation. Without maintenance of these parameters, the patient may become unstable and a donation opportunity lost. In this instance, a transfer solely for the purpose of donation may be appropriate but must be clearly communicated to the family before transfer.

\section{What are other key considerations for the patient and family while in the emergency department?}

Social, psychological, and spiritual support of the patient and family are key components of high-quality health care. For families, this process starts on arrival to the hospital. Proactive interventions, such as social work involvement, family rooms, and spiritual care support, have shown some success in mitigating psychological distress and its sequelae. 


\section{Organ Donation in the ED}

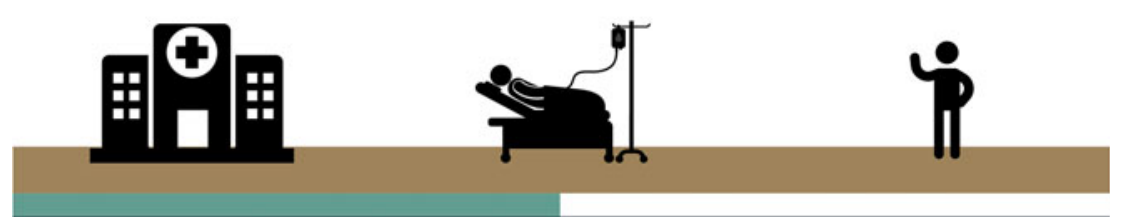

\section{Canada is underperforming with organ donation rates}
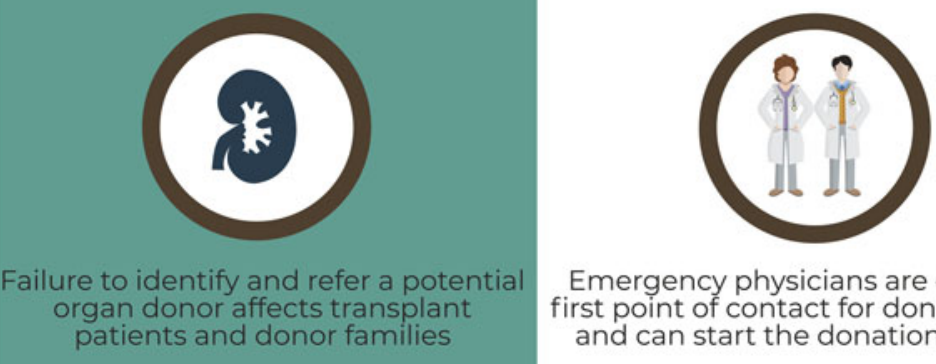

Emergency physicians are often the first point of contact for donor families and can start the donation process

\section{What are the clinical triggers for organ donation?}

Mechanical support of cardiac

\& respiratory function
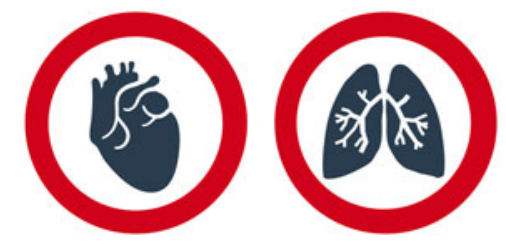

Condition with grave

prognosis in which:

\section{What are the next steps in organ donation?}

\section{Referral}

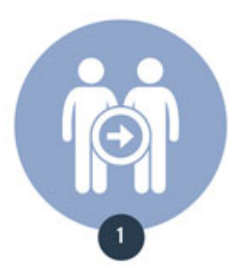

Patients who meet clinical triggers must be referred to an Organ Donation Organization
Medical Support

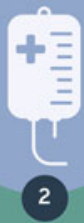

Normal physiological parameters should be aintained to prevent losing a donation opportunity
Comfort \&

Emotional Support

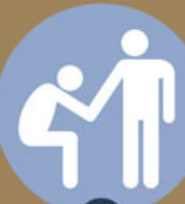

3

Social, psychological and spiritual support of the patient and family help mitigate psychological distress

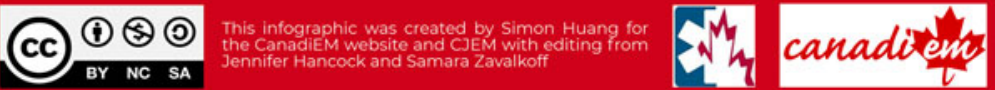




\section{In what setting should the opportunity for donation be offered to the family?}

These difficult conversations should be led by donation experts and only be held after a family are accepting of a diagnosis of neurological death or a decision has been made to withdrawal life sustaining measures. It is preferable for discussions about donation to be held in a separate meeting from the end of life discussions. ${ }^{5}$

In Canada, however, regional system organization and practice may preclude donation experts from leading these discussions. If this is the case at your institution, the case should be discussed with your local organ donation organization before any organ donation conversations with family. This will ensure the patient is medically suitable before offering the opportunity to family and will also provide support and education to the health care team. ${ }^{5}$

\section{CASE RESOLUTION}

The patient was supported in the emergency department until transfer was arranged to a neurosurgical intensive care unit. Over the next 72 hours, the patient was assessed and deemed to have a nonsurvivable injury. Withdrawal of life sustaining measures was recommended. This was communicated to the family and support was provided by spiritual care and social work. The organ donation organization was formally consulted, and collaboratively the team offered the family the opportunity for organ donation. The patient progressed to neurological death and successfully donated four organs.

Keywords: Critical care, emergency medicine, transplant medicine

Acknowledgements: We acknowledge CanadiEM for their development of the infographic accompanying this manuscript.

Financial support: Contracted by Canadian Blood Services to develop an e-learning curriculum on deceased donation for health care professionals. Received grants from Canadian Blood Services and Health Canada for research and quality improvement work on organ donor identification and referral.

Competing interests: Dr. Hancock receives support from Canadian Blood Services to develop a deceased donation e-learning curriculum for healthcare providers. Dr. Zavalkoff received an award from Canadian Blood Services and a grant from Health Canada for work related to identification and referral of potential organ donors.

\section{REFERENCES}

1. Wojda TR, Stawicki SP, Yandle KP, et al. Keys to successful organ procurement: an experience-based review of clinical practices at a high-performing health-care organization. Int 7 Crit Illn Inj Sci 2017;7:91-100.

2. Zavalkoff S, Shemie SD, Grimshaw JM, et al. Potential organ donor identification and system accountability: expert guidance from a Canadian consensus conference. Can 7 Anaesth 2019;66:432-47.

3. Canadian Blood Services. 2018. System Progress Report - 2017 Update. Available at: https://professionaleducation.blood.ca/sites/ msi/files/system_progress_report_2017_update_final_en_7.pdf (accessed July 25, 2019).

4. Callaway CW, Donnino MW, Fink EL, et al. Part 8: post-cardiac arrest care: 2015 American Heart Association guidelines update for cardiopulmonary resuscitation and emergency cardiovascular care. Circulation 2015;132 S465-82.

5. Shemie SD, Robertson A, Beitel J, et al. End-of-life conversations with families of potential donors: leading practices in offering the opportunity for organ donation. Transplantation 2017;101:S17-26. 